\title{
Gendered representations of fatherhood in contemporary South African church imagery from three Afrikaans corporate churches
}

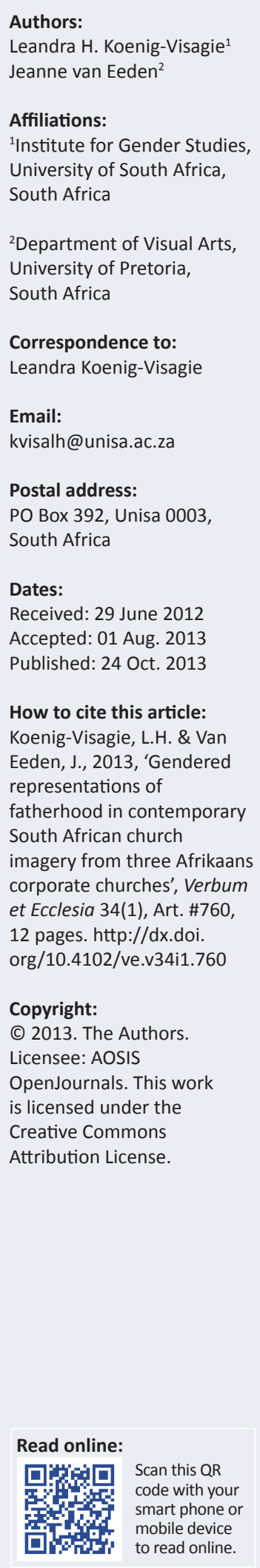

Authors:

Leandra $H$. Koenig-Visagie

van Eeden

South Africa

University of Pretoria

\section{Correspondence to:}

Email:

PO Box 392, Unisa 0003

Dates:

Accepted: 01 Aug. 2013

How to cite this article: Koenig-Visagie, L.H. \& Van Eeden, J., 2013, 'Gendered representations of South African church imagery from three Afrikaans corporate churches', Verbum et Ecclesia 34(1), Art. \#760, 12 pages. http://dx.doi.

Copyright: Creative Commons Attribution License.
The South African secular media do not frequently portray men in parental roles; on the other hand, it seems that media and visual culture created by the Christian sector is more likely to engage with issues of fatherhood. Accordingly, it is relevant to explore representations of fatherhood in the Christian context, as these constitute some of the few examples of men's parental roles in the South African visual culture landscape. Through a Barthean visual semiotic analysis, this article describes and problematises the representation (and non-representation) of certain aspects of fatherhood in the recent visual culture of three Afrikaans corporate churches in the Pretoria-Centurion area. It further establishes that strong connections between breadwinning, male headship and fatherhood exist in images created by these churches. Fathers are mainly shown as patriarchs, heads of households and as active outdoor adventurers. We argue that although men are depicted as involved parents, there are certain limitations and exclusions to this involvement.

\section{Introduction}

According to David Morgan (2001:231-232), the study of the family is important for gender analysis, since the family can be regarded as a microcosm for broader gender relations in society. Conversely, ideologies that aim to affirm masculine hegemony seek to control this microcosm. In a Christian context, religious traditions and practices are, to a certain degree, generally believed to be sacred and are not easily or openly challenged by followers of such practices. As in the past, contemporary church imagery is often considered to be authoritative, didactic and hegemonic, and this historical tendency also translates into its prescriptions regarding Christian gender roles and the configuration of the family. Furthermore, from a gender perspective, and specifically from a performative view of gender (Butler 1990), representations of men and women comprise the 'gender scripts' (Whitehead 2002:170) that culture provides for the proper performance of gender roles (Brod 1995:15). As such, gendered portrayals become idealisations of manhood and womanhood. Consequently, it can be assumed that the visual culture which a church produces models certain ways of being a man or woman that represent the gender scripts that the church advocates for its members.

This article explores gendered representations (and non-representations) of fatherhood in the visual culture of three Afrikaans churches in the Pretoria-Centurion area, namely the Dutch Reformed Congregation Moreletapark, the Dutch Reformed congregation kerksondermure and the Apostolic Faith Mission organisation Doxa Deo, based on a visual sample of the churches' promotional material from 2006 to 2008 . The visual sample includes printed material, such as brochures, flyers and announcements, as well as electronic materials, such as images from websites. The findings regarding fatherhood discussed in this article form part of a larger study on the representation of gender in the three Afrikaans churches referred to above (see KoenigVisagie 2012a, 2012b). This larger study focuses on the representation of masculinity and considers the data regarding masculinity according to three themes regarded as central to adult masculine identity, namely professional occupation and leadership; physical activity and adventurism; and fatherhood. The representation of femininity is also considered in this study, but it is found to be constructed mainly as a visual counterfoil to the manner in which the male is constructed; the female is, accordingly, visually constituted in the data as everything the male is not and as his essential and binary opposite (see Koenig-Visagie 2012a:150). This study thus found that a binary ideology of gender is at work in the visual material generated by the three churches investigated.

We believe there is a need for a discussion that highlights the representation of fatherhood in this larger study, because the South African secular media do not frequently portray men in parental roles (Prinsloo 2006:132), as we will discuss later in this article. Yet, media and visual culture created by the Christian sector is more likely to engage with issues of fatherhood (cf. Viljoen 2008, 
2011). Accordingly, it is relevant to explore representations of fatherhood in the Christian context, as these constitute some of the few examples of men's parental roles in the South African visual culture landscape.

The study employs a visual Barthean semiotic analysis, which views a visual text as a unit of analysis in its own right. In its most basic form a semiotic analysis is concerned with meaning and levels of meaning - that of denotative (literal), connotative, mythical and ideological meaning. These meanings are connected to signs, which comprise both signifiers (vehicles for signs) and signifieds (concepts referred to by signs). Semiotics was originally applied to linguistic analysis, but through the work of, especially, Roland Barthes ([1957] 1972), this approach finds wider application, most noticeably in post-structural analyses of culture. When applied to the analysis of visual culture, the linguistic principles semiotics appropriates are applied to visual language as a representational system akin to that of verbal or written language. Through a visual semiotic analysis, the levels of meaning mentioned above are thus revealed through an analysis of the visual text. A Barthean semiotic analysis, in particular, focuses on mythical and ideological meanings. The concept of myth in Barthean semiotics is defined as cultural myth as opposed to narrative myth, such as folklore. Cultural myth is created by a society, mainly in order to naturalise dominant ideologies in that society (Barthes [1957] 1972:137-141). In the case of this study, Barthes' approach is used to demystify and denaturalise the conservative and essentialist ideas regarding fatherhood that are conveyed in the churches' imagery.

The following five sections of this article introduce some of the main ideas in academic discussions around fatherhood. We consider fatherhood and its related male identity concerns; media representations of fatherhood; crisis in masculinity theory and how it is related to fatherhood; the new man or new father paradigm; and certain ideas specifically related to Christian fatherhood. After we have covered these topics, we move on to a discussion of the findings of the visual semiotic analyses conducted on images of fatherhood collected for this study. This discussion will demonstrate that fathers are visually conceptualised in the three churches investigated as heads of households and patriarchs, as physically active and engaged in male bonding, and as involved parents in the family context. We argue that although men are depicted as involved parents, there are certain limitations and exclusions to this involvement. We also refer to the representation of motherhood, where appropriate, but this is not the focus of the discussion. The exclusions and limitations to the representations of involved fathers are then problematised in the context of the larger study.

\section{Fatherhood and male identity}

... the masculinist trajectory of the heroic successful patriarch provides the naturalised discourse for society and other media narratives. (Prinsloo 2006:138)
Richter and Morrell (2006:1) stress the social role aspect of fatherhood and believe that the content of this role shifts, as does its relative importance. Although fatherhood is a fluid concept - as indeed masculinity itself is considered multiple - certain ideas and ideals remain persistent, especially in the case of conservative and traditional fatherhood. Surprisingly, White, traditional fatherhood is underresearched in the South African context, especially regarding its visual representation, because in most cases it has become so synonymous with the fatherhood ideal that it has become practically invisible, or ex-nominated, in Barthean ([1957] 1972) terms. Stella Viljoen's $(2008,2011)$ work on fatherhood in the now defunct Afrikaans Christian men's magazine, MaksiMan, does, however, shed some light on White Christian fatherhood in South Africa. Similarly, Susan Faludi's (2000) research on the Northern American, anti-feminist, Christian men's movement, the Promise Keepers, also touches on issues of fatherhood in relation to Christian masculinity. The overview of the issues related to fatherhood in this section serves to introduce some of the leading concepts in the discourse but does not aspire to a comprehensive discussion thereof. The discussion below is mostly based on research and literature originating from South Africa, North America and the United Kingdom.

An important distinction is generally made between being a father - a biological act - and assuming the role of fatherhood - a social act. Accordingly, men do not necessarily accept the social role of fatherhood after becoming biological fathers (Morrell 2006:14). Nevertheless, the mere act of begetting a child can reflect the transition into manhood, as it represents biological and reproductive accomplishment, or 'genital success', as David Cohen (1990:169) refers to it (see also Morrell 2006:13, 16-17). Regardless of the levels of willingness to participate in fatherhood on the part of the biological father, begetting a child is considered the primary signifier of achieving adult manhood as it carries associations of commitment and assuming responsibility (Clare 2000:166; Marsiglio \& Pleck 2005:256; Morrell 2006:15; Richter \& Morrell 2006:5). A father is traditionally viewed as the provider for and protector of his wife and children (Clare 2000:184-185; Marsiglio \& Pleck 2005:256, 259). These dual responsibility roles towards wife and children sometimes results in a conflation of the husband and father roles (but see also Morrell [2006:17]). The male breadwinner construct is consequently central to traditional notions of fatherhood and, in turn, to masculine identity. According to Whitehead (2002:151), through the breadwinner construct men can, or could, achieve a 'sense of masculine validation through their ability to feed and support their family'. This idea of men's ability to provide for their families as fathers is foundational to the adult male identity ideal. In this psychosocial construction and ideal, being a man means being a father (Morrell 2006:15), and being a father means being the breadwinner (Clare 2000:188). David Morgan (2001) states that:

Male identity revolves around notions of the breadwinner, the assumption of mature adult responsibilities in terms of a wife and children, the settling-down into respectability, duty and 
security. There may be masculine identities other than that of the breadwinner, but this is clearly the dominant one and other identities ... derive their meaning in part from their relationship with this central signifier of masculine identity. (p. 226)

In the study's data on which this article is based, various depictions of breadwinning are found, mostly in the form of portrayals of corporate masculinity and male professional leadership. These elements are also present in Viljoen's (2009) analysis of MaksiMan. In the construction of masculinity, there is thus a connection between breadwinning and fatherhood and this manifests itself in South African, Afrikaans, Christian visual culture (cf. Koenig-Visagie 2012a:87, 104, 129-130).

Despite its centrality in many a cultural imaginary, numerous scholars would agree that the breadwinner construct is mainly a middle-class phenomenon. In South Africa, middleclass men are likely to be able to take up a fatherhood role, which entails being a protector, provider and caregiver, as they have the necessary means and time to do so (Morrell 2006:22). Springer (2007:6) points out that extensive research shows how, historically, the family unit based on the male breadwinner and female homemaker was only a viable option for (upper-) middle-class families. Accordingly, Morgan (2001:226) connects the rise of the breadwinner model with the rise of middle-class dominance. So even though the ideal of the father-breadwinner is persistent, it appears to be just that, an ideal. In this regard Brittan (2001:52) also asserts that the breadwinner ideal remains dominant, although in practice extinct, with most middle-class families having to rely on dual sources of income.

\section{Fatherhood in the media}

The work of Prinsloo (2006) offers one of the few appraisals available of the representation of fathers in the South African media. Prinsloo considers the South African media in a broad sense and includes examples in her work of both fictional media narratives, such as those found in television and film, as well as non-fictional media narratives, such as those found in news reportage. She identifies two problems with the representation of fatherhood: firstly, the South African media very seldom depict men in parental roles, but when depicted the repertoire of roles for fathers is very small; secondly, violent macho roles, where the representation of men is concerned, are portrayed more frequently and tend to act as a substitute for male parental roles (Prinsloo 2006:132). This rare depiction of fathers and the limited scope for paternal roles portrayed contradicts the widely held belief that the media portrays a variety of masculinities (Prinsloo 2006:135). The relative invisibility of fathers in the South African media also echoes Viljoen's (2011:310) assertion that men are not represented as fathers or husbands in mainstream men's lifestyle magazines in South Africa, which aim to create a carefree space for men, liberated from the constraints of parenthood and marriage.

On the other hand, media and visual culture generated by Christian producers exhibit a willingness to engage with matters of fatherhood, as opposed to the secular mainstream media which seems to avoid them. This tendency of Christian media and visual culture to portray fatherhood more readily is also evident in Viljoen's $(2008,2011)$ research on MaksiMan. As some of the rare representations of fatherhood in South African visual culture come from Christian visual culture, it is paramount in an investigation of fatherhood to consider these texts as part of the limited amount of South African 'scripts' available on male paternity.

Notwithstanding the lack of representation of fatherhood in the media, especially when compared to the abundance of violent and macho roles depicted, the following is noted when fathers are in fact portrayed in the media. Prinsloo (2006:133, 135) points out that although the South African media does not foreground fatherhood, the normality of heterosexuality and fatherhood is assumed in media depictions and patriarchy is thereby upheld. Fatherhood is frequently constructed in its breadwinner function in the public domain. In this regard, Richter and Morrell (2006:4) state that, 'men continue to be characterised in the public rather than the domestic realm. This ... bolsters broader patriarchal power relations that assign the unrecognised responsibility for childcare to women.' In the spirit of Ortner's ([1972] 1998) argument that women are devalued because they are seen as close(r) to nature, Prinsloo (2006:134) contends that fatherhood is perhaps devalued because it is associated with the feminine domestic realm. It then stands to reason that men are not frequently portrayed by the media in their paternal roles, as such representations may locate them closer to or in the domestic realm. Media representations prefer to locate fathers in challenging settings related to physical endurance, or in the public realm of the workplace (Prinsloo 2006:134).

In other instances where fathers are indeed portrayed in the mainstream media they are often demonised and stereotyped as pathological and as bad influences on their families, especially on their children. When represented, fathers are sometimes framed as the perpetrators in child abuse and sexual molestation. This is particularly the case in South African news media, where fathers are represented in connection to family and property disputes as well as murder and child abuse (Prinsloo 2006:142). But these preconceived notions should be questioned and evidence supporting these claims should be considered in context. For example, as far as child abuse is concerned, the media suggest that it is often fathers who are involved in the crimes, but, contrary to popular belief, a very low percentage of fathers abuse their children (Clare 2000:185).

Clare (2000:166) believes that, when fathers are depicted in the media they are represented as either heroes or villains, and such portrayals represent very little serious discourse around fatherhood. Father-villains are often portrayed as absentee fathers who do not live with their children (Clare 2000:166). The 'deadbeat dad' is considered a pervasive and stereotypical image of the father (Marsiglio \& Pleck 2005:255). Fathers are thus not only portrayed in the media as pathological and absent, but also as generally inadequate 
as parents. Hence, one might argue that the problems that Prinsloo (2006:132) identifies with the representation of fatherhood reaches further than the under-representation of fatherhood by the media. It also, and specifically, includes the under- and misrepresentation of domestically engaged fatherhood. This argument would, however, be in keeping with her proposal that when represented, the repertoire for fathers is very small.

\section{Is fatherhood in crisis?}

The notion of fatherhood encapsulates various issues related to the so-called crisis in masculinity hypothesis whereby men are believed to be uncertain about their roles in contemporary society (cf. Whitehead \& Barrett 2001:8). Accordingly, women are often stereotyped as the primary caregivers of children (Clare 2000:161, 164; Day \& MacKey 1986:382; LaRossa 1995:451) and as a result, men are less involved in primary childcare, spending much less time on such tasks than women do (Whitehead 2002:153). Men's position as breadwinner, or working man, legitimises their absence from care giving tasks and often from the home itself. In this sense, men are kept away from the family owing to demands of work (Cohen 1990:175). According to Whitehead (2002:154), 'men's relative absence from the private sphere is further embedded in and validated by a performative work culture and government policies.' This legitimised absence of the father feeds conventional and conservative gender role expectations, such as the notion that, because a father ideally should work, it is the woman's responsibility to look after the children (Cohen 1990:172). These beliefs are, of course, not just based on simple economic experience, but are also ideologically founded. It may be true that economic forces are mainly to blame for gross absenteeism amongst fathers, but according to Cohen (1990:175), it stands to reason 'that men have not agitated for a change in the structure of work, because it suits them to have women burdened with the care of children'.

Absenteeism is a phenomenon commonly associated with South African fatherhood (Richter \& Morrell 2006:2). The country's legacy of migrant labour resulted in the fact that black fathers worked in distant locations, with limited visits to their homes. Morrell (2006:20) cites severe poverty and resultant feelings of inadequacy as breadwinners as another reason why South African men shrink from their paternal role. In South Africa, 50.2\% of African children do not have their living father present in their residing household (Posel \& Devey 2006:47). When compared to this figure, the $10.9 \%$ of White children (Posel \& Devey 2006:47) who do not have their living father present seems fairly small. Morrell (2006:18), however, draws attention to the fact that paternal absenteeism cannot be defined only in terms of physical absence. Emotional absence also plays an influential role in children's lives. In describing the absent and emotionally distant father as portrayed through the South African literary imaginary, Morrell (2006) states the following with regard to White South African men:
The fathers consist of a combination of unequal and careless relationships with women, children and people of colour or other religions and beliefs; unquestioning self-belief and bluster; and a preference for physically demanding homosocial contexts. This form of masculinity is often considered to be dominant among white South African men. Even though other expressions of masculinity exist, it is the values and behaviours of these men that are accepted as 'normal' and, indeed even lauded. (p. 19)

Although the majority of White South African fathers seem to be present in the household, there are various factors which suppress their involvement. Viljoen (2011:314) describes the impact of corporate globalisation as such a factor. Companies are increasingly demanding more availability and higher productivity from their workforce, who are expected to be flexible and able to travel when necessary (Viljoen 2011:314). As this is the likely working scenario for middle-class employees, one can assume this is the case for working fathers (and mothers) in Pretoria East and Centurion.

The above scenario is only applicable to middle-class fathers who are lucky enough to have a job. The South African employment equity agenda has resulted in large-scale retrenchment, especially of White men. As mentioned above, unemployed fathers are faced with a crisis in terms of their provider role. A final factor that has contributed to the absence of working fathers is poor provision for paternity leave in South African labour law. Fathers may only take a few days of 'family responsibility' leave in order to attend to serious family business (Richter \& Morrell 2006:3). With ample provision for maternity leave, South African women are stereotypically coerced into the caregiver role and South African men are forced into the provider role (Viljoen 2011:315).

But with women moving into the public sphere of the workplace and seeking paid employment outside the home, ideals of traditional nuclear family structures are shifting (Morgan 2001:227), and men's identities as breadwinners are fundamentally challenged. Contributing to this are higher instances of divorce, resulting in a further decline in the traditional nuclear family (Whitehead 2002:152). In South Africa, traditional family configurations are not only under threat for the reasons discussed above, but also from a high mortality rate amongst adults owing to the HIV and AIDS pandemic (Richter \& Morrell 2006:6), resulting in single parenthood and child-headed households.

This change in the traditional family structure, or 'crisis' according to certain right-wing politicians and fundamentalist religious leaders, constitutes a crisis for masculinity, as it threatens patriarchal power in the home, resulting in a phenomenon also referred to as the 'death of the patriarch' (Clare 2000:120). According to hypotheses of the crisis in masculinity, men are, seemingly, in real danger of being rendered redundant and declared irrelevant (Silverstein et al. 1999:684). This is a particularly ideologically vexing problem in conservative Christian households. A loss of power for men is therefore signalled in both the workplace and at home (Morgan 2001:228). 


\section{The new man or new father}

There are, and have always been, different types of families, and indeed, different ways of living out and experiencing fatherhood (cf. Whitehead 2002:153), which is in line with current broader theoretical notions of the existence of multiple masculinities (Morgan 2001:223). An alternative form of masculinity that has received a considerable amount of publicity over the past few decades is that of the 'new man', who 'appears to have engaged in a re-negotiation of domestic involvements and ... actively and publicly engages in child-care and child responsibilities' (Morgan 2001:228). 'Fathering', according to Cohen (1990:168), 'is in fashion'. In line with the ethos of the 'new man' paradigm, stay-at-home fathers, or househusbands, have also started to emerge. The idea of the 'new man' or 'new father' is commonly represented in contemporary films, such as About a boy (Weitz \& Weitz 2002) and The switch (Gordon \& Speck 2010) as well as in popular television shows, such as Who's the boss? (Cohan \& Hunter 1984-1992) and Two and a half men (Aronsohn \& Lorre 2003-2012), to name but a few. Prinsloo (2006:138) mentions that the new man is portrayed, especially in advertising, as being able to invest himself emotionally in relationships, and as wanting to spend quality time with his children.

Nevertheless, 'new fathers' appear to be 'choosy' about which part of childcare they become involved in (Cohen 1990:177). Women are chiefly tasked with the less savoury duties of childcare, such as cleaning up and preparing meals, whilst fathers are more likely to be involved in playing with the children (LaRossa 1995:451). Whitehead (2002) also questions the actual impact of this paradigm of new masculinity, as he believes that:

[ $w$ ]hile being a 'new father' implies a break with increasingly dated ideas of traditional male roles, and therefore carries with it some cultural capital for men, in practice it can often mean little more than a symbolic attachment to the idea of being father rather than a full, equal, and unmitigated engagement in its harder practices. (p. 154)

Similar to this view is Ralph LaRossa's (1995:448) belief that whilst the culture of fatherhood has changed in the United States of America, the behaviour of fatherhood lags behind. Silverstein et al. (1999:665) echo this sentiment by stating that, 'masculine gender role socialization has not kept pace with the rapid social changes that families have been experiencing.' Even though men are no longer the sole providers in families, the concept of nurture has not yet been deemed central to the masculine role in various cultural ideologies (Silverstein et al. 1999:665). Various theorists also agree that the 'new man' or 'new father' phenomenon remains, predominantly, like the breadwinner myth, a middle-class phenomenon (LaRossa 1995:457). Morrell (2006) explains the cause of this middleclass trend:

[W] here material circumstances are secure (because men have reliable and sufficient incomes), fathers may be expected to participate in more engaging ways with their children. In this context, where time and money are not an issue, the new fathercaring, domestically engaged and demonstrably loving - is more likely to be the model. (p. 22)
Nonetheless, Whitehead (2002:154) affirms that, 'traditional gender stereotypes remain resilient in many cultures', and believes, owing the allure of the public world for masculinity construction, the 'new man' and 'new father' to be rare.

\section{Christian fathers}

Certain ideas around traditional fatherhood are specifically related to Christian fatherhood. The concept of male headship is powerfully embodied in the figure of the father, or in some cases the patriarch, as the head of the family. Indeed, patriarchy, in literal terms, is understood to mean the 'rule of the father' (Morgan 2001:225), and one of the most visible forms of patriarchy is embodied by 'the father' and, to some extent, by 'the big business executive'. The idea of male headship of the household, implying the father or husband's headship, is especially dominant in Christian discourses concerning fatherhood, and imbues the father or husband with Godlike authority and a moral imperative to lead, or head up, his household. In this discourse, the human father is thus likened to God the Father and he is, therefore, deserving of the same degree of respect and obedience. Being a good father and husband is thus considered a Christian masculine ideal (Viljoen 2011:311, 318). Such ideas are also found in conservative Afrikaner Christian households, which often adhere to these beliefs. In reflecting on Afrikaner gender identity in the first half of the 20th century, Du Pisani (2001) notes that:

Puritan Afrikaners viewed the male-headed family as the cornerstone of a healthy society. The image of the male head of the family was cast in the mould of the 'good provider' ... Afrikaans churches have held the view that the male head of the family should fulfil a priestly function, by not only providing his family with material things, but also looking after their spiritual well-being. (p. 163)

In the Afrikaner context, fathers were thus historically constructed as both the material and spiritual providers for their families.

Changes in the family structure and challenges to patriarchal power have resulted in a backlash by conservative and fundamentalist movements. Promise Keepers, for example, disseminate an essentialist view of fatherhood (Marsiglio \& Pleck 2005:251), and the parenting roles of men and women are conceptualised as uniquely masculine or feminine, as well as universal. In their investigation of fatherhood amongst Promise Keepers men, Silverstein et al. (1999:667) believe that, ' $[n]$ eoconservative ideology generally promotes a hierarchical power relationship of male dominance over women in families. It defines parenting roles as linked to biological differences between men and women.'

Studies on the Promise Keepers conducted by both Silverstein et al. (1999) and Faludi (2000) describe the movement's neoconservative and fundamentalist ideologies. Both these studies found that the views espoused by the leaders of Promise Keepers are much more political and reactionary than those of their grass-roots members. There are therefore mixed messages arising from the Promise Keepers movement: 
the fundamentalist views of the leaders, as opposed to the more temperate and negotiated views and lived experiences of the men involved in the movement. Most Promise Keepers men are merely trying to be better husbands to their wives and better fathers to their children. Promise Keepers leaders, however, stress a return to traditional father roles, and urge men to 'take back the mantle of responsibility as leader of the family' (Silverstein et al. 1999:667). In this light, another confusing message disseminated by the Promise Keepers is that a man must lead by serving, as Jesus did. Using Jesus, as a loving God, as role model, Promise Keepers men aspire to become more nurturing fathers (Silverstein et al. 1999:674). Being good fathers also gives the men a feeling of a more profound connection to God the Father.

Faludi (2000:240), however, points out that Promise Keepers' ideology makes it possible for men, in the face of so many threats to their masculine power, to remain the head of their households, albeit not the economic heads (cf. Whitehead \& Barrett 2001:7). This line of thinking is comforting to men holding on to traditional ideals of Christian manhood, as Silverstein et al. (1999:681) contend that, this 'reassured them [men] that, although they were giving up some of the power associated with an authoritarian stance, they were still the leader of the family'.

\section{Representations of fatherhood in church imagery}

Taking into account the issues touched on above, a discussion of findings of the visual Barthean semiotic analyses of the representation of fatherhood in selected images from the visual communication obtained from Moreletapark and kerksondermure now follows. No visual representations of fatherhood were found in the data collected from Doxa Deo, which we will comment on later in this article. It is clear that the images discussed below reproduce a conservative ideal of fatherhood that in all probability may not align with the everyday experiences of the men to whom they are addressed. The images discussed here comprise a banner from Moreletapark's website for their Family Ministry (Gesinsbediening) (Figure 1); the front cover of a kerksondermure $\mathrm{ksm}$ magazine (Figure 2) and the two advertisements for Moreletapark's Father and Child Camp ( $P a$ en kind kamp) (Figure 3 and Figure 4). An advertisement for Father and Son Paintball (Figure 5) is followed by a discussion of a file meant to contain material for Moreletapark's baptism course for parents (Figure 6).

On the left side of Figure 1, one sees a photograph of a man, a woman and a child who are engaged in an embrace. From the context of the photograph being associated with family ministry, one assumes that the figures represent a husband, wife and child; or a father, mother and daughter. In their embrace their faces are pressed together, giving the sense that one is witnessing a loving and intimate moment. The woman and the girl both have blond hair, which not only suggests that they are biologically related, but also associates them with each other visually. A certain degree of connotative conflation occurs in this photograph between woman and child.

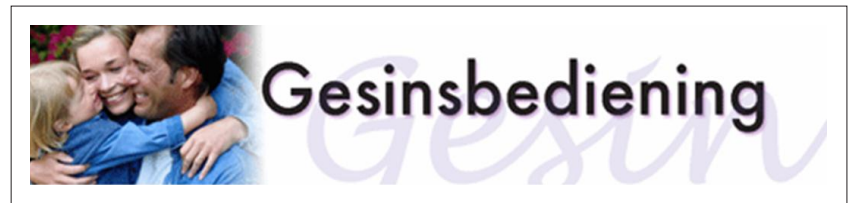

Source: Moreletapark Gemeente, Gesinsbediening, viewed 14 August 2008, from http:// www.moreleta.org/NGGM/Users/PortalPageEdit.aspx?Cat=86\&SubCat/D=81\&Menultem= tem_81

Used with permission by the Dutch Reformed Congregation Moreletapark.

FIGURE 1: Moreletapark 'Gesinsbediening' (Family Ministry) website banner.

All the figures are smiling happily, thus representing the myth of the happy nuclear family. The dominant colour in the photograph is blue, which is used for the clothing the figures wear, but there are also some deep pink flowers in the background. This could be interpreted as a polarised and gendered use of the colour of pink versus blue: the dominant use of blue, with pink only in the background, could perhaps subtly hint at male headship and masculine dominance in the family. Similarly, the fact that more of the male figure is visible in this image also renders him the visually dominant figure. Nevertheless, this banner represents the father-figure as present, engaged and involved in a loving and intimate family moment. This banner does, however, contain ideological traces of patriarchy and compulsory heterosexuality, as it is a man and a woman shown in a romantic relationship in a traditional family configuration.

The front cover of kerksondermure's ksm magazine from October 2008 (Figure 2) contains various references to a congregational Harvest Festival (Oesfees). The photograph on the magazine cover shows a male figure surrounded by three women. He is one of the ministers at kerksondermure and the women are his wife, who visibly displays a wedding ring, and daughters. They are sitting outside under the trees - an image which holds connotations of closeness to nature in terms of the Harvest Festival. From their physical proximity to one another one deduces that they are a close-knit family. Similar to Figure 1, the male father-figure is portrayed as being a present, involved, engaged and loving member of the family unit. The fact that the entire family, including the male figure, is located in nature is worth noting, as it has been suggested that closeness to nature is a stereotypically feminine trait. Visually locating the male figure in nature, as opposed to showing him attempting to conquer nature, is a progressive move in terms of gender representation. Nevertheless, the male father-figure is still portrayed as the head of the family, as described below.

As in Figure 1, all the members of the family have big smiles on their faces and again typify the myth of the happy nuclear family. In this sense, the minister and his wife represent a heterosexual married couple, with children - the conventional formula for the nuclear family, which supports myths of compulsory heterosexuality and patriarchy. The portrayal of a family in conjunction with the Harvest Festival ties together ideas of gratitude and abundance with notions of family values, as well as values of human reproduction an idea that has an important place in Christian ideology. To the right of the family, there is a large black cow, which could 
have been included here to connote ideas connected with the harvest, as well as wholesomeness and naturalness, but also signifies the agricultural roots of the Afrikaner people as farmers, or boere.

The women in the photograph are not represented as hyperfeminine; female signifiers such as long hair, jewellery, makeup and breasts are visible but not emphasised. Instead, it is their wholesomeness that is emphasised in this Christian context and one assumes this supports ideas around the Harvest Festival. The women are lovingly laying their hands on their father or husband's shoulder and the family is holding hands, acting as a sign of intimacy, love and adoration. In this sense the male figure appears as the venerated and respected patriarch of the family, the head of a household of women. His roles as husband and father are merged, and so are the roles of his wife and daughters. The father-figure is also, accordingly, situated in the middle of the composition and is thus portrayed as the most prominent figure. Sitting on a rock or stone, the picture portrays him as being the 'rock' of the family - an identification with Jesus as the rock of the Church. The minister and his family are public figures in a church community and this family is often employed stereotypically as a role model family unit in the church hence their appearance on the congregation's magazine.

Op pad (En route), Moreletapark's magazine, advertises a 'Pa E kind-kamp' (Father and Child Camp) in their October issue of 2008 (Figure 3). The camp advertisement contains a body of text and a photograph of a male adult hugging a child in front of him. Owing to the context of the photograph in the advertisement, one assumes that they are father and son. The father is wearing a t-shirt and sunglasses, signifying that he is outside in the sunlight. His dress connotes a casual outdoors look and he is staring away into the distance to the right. The son is nestled under his chin and appears to be of a different race than the father. This representation is rather strange in the context of Moreletapark. As is the case with all the churches in this article, the Moreletapark congregation has very few Black members, and Mixed race couples and families are outliers. It is, therefore, highly unlikely that Figure 3 constitutes a realistic portrayal of father-son relationships in Moreletapark. In this regard, the image does, however, deserve some credit for the manner in which it complicates traditional patterns by suggesting that a man might be nurturing a child that is not his own. The image also potentially deconstructs conventional expectations regarding race in the family.

Like his presumed father, the boy is also staring out of the picture plane to the right. The fact that the two figures are staring away into the distance gives the idea that they are outdoors in nature, looking at something, enjoying the view, and gazing at the landscape. The edges of the photograph containing the father and son are irregular and intruded upon by thin strokes from the outside of the frame. These fine lines could be understood to suggest blades of grass, thereby creating the sense that they are outside. The father-and-son

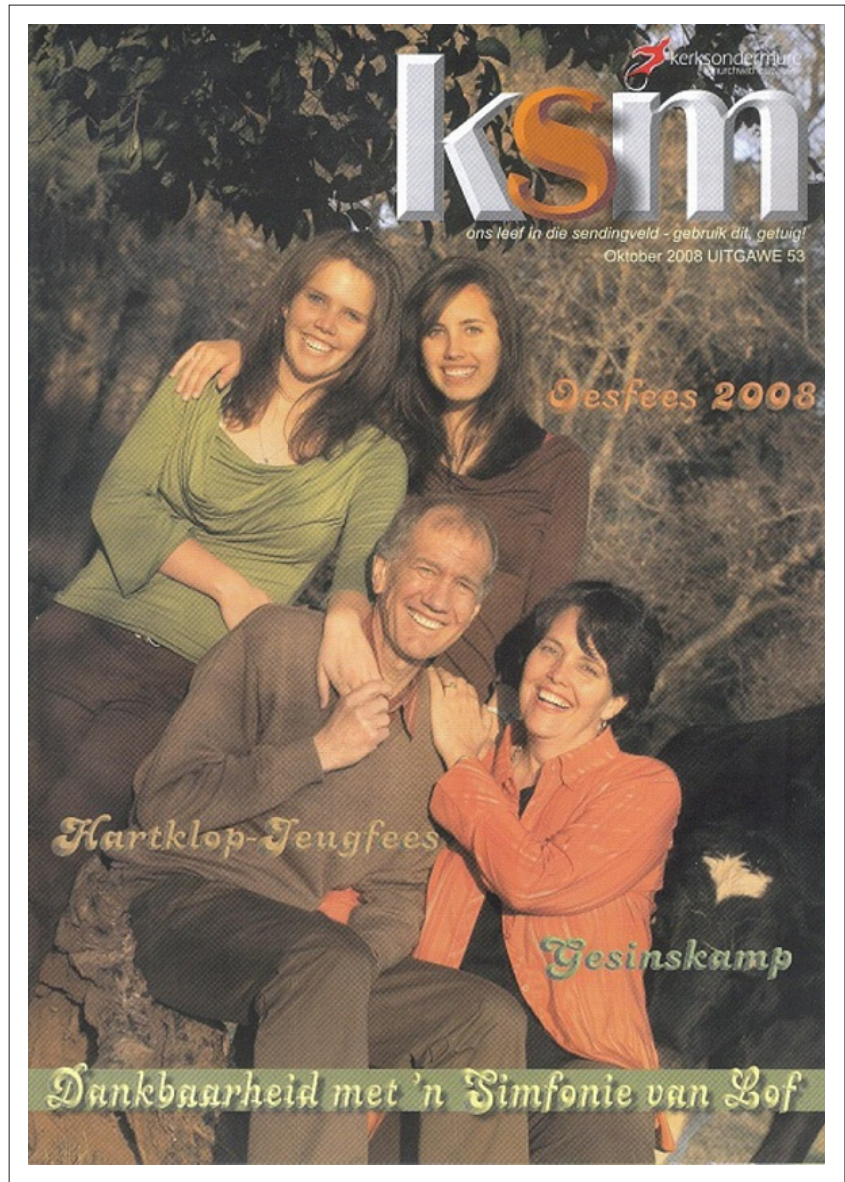

Source: $k s m, 2008$, Oktober (53), p. 1

Used with permission by the Dutch Reformed Congregation kerksondermure.

FIGURE 2: Kerksondermure front cover of ksm magazine, October 2008.

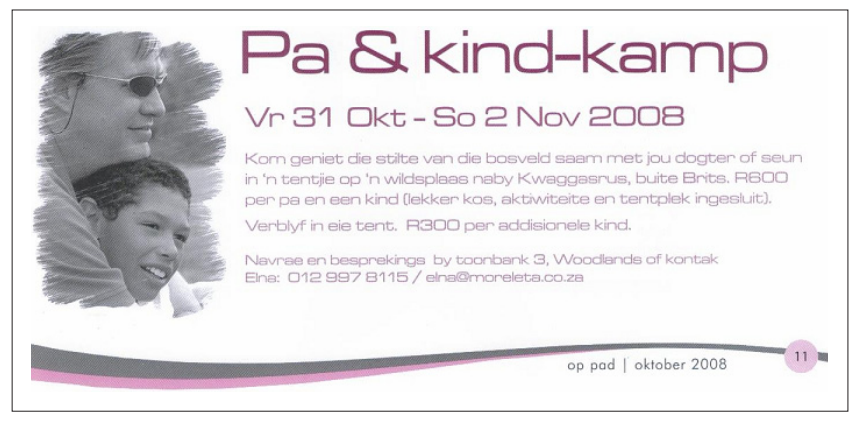

Source: Op pad, 2008b, Oktober, p. 11

Used with permission by the Dutch Reformed Congregation Moreletapark.

FIGURE 3: Moreletapark 'Pa \& Kind-kamp' (Father and Child Camp) print advertisement in Op pad magazine, October 2008.

pair is visibly engaged in male bonding in the outdoors, but we are also again witness to an intimate moment of paternal involvement, shown through the loving embrace in which the father-figure wraps his son.

Figure 4 also represents an advertisement for the Father and Child Camp, but in the form of a flyer that was included in the printed Sunday service announcements. This flyer has a fairly masculine design with the same bold, static sans serif font and rigid grid layout structure as in Figure 3. The light scribbling around the font for 'Pa en kind' (Father and Child) and 'Navrae' (Enquiries) shows some attempt to make the 
flyer appear less formal, but in its totality the flyer is quite serious for a camp where there will be playing, outdoor activities and sleeping in tents. From Figures 3 and 4 one notices that an emphasis is placed on father and son bonding through physical activity. This emphasis is also seen in an advertisement for Father and Son Paintball (Figure 5) in Moreletapark's Op pad magazine of September 2008.

The Father and Child Camp flyer (Figure 4) has basically the same text as the advertisement in Op pad (Figure 3) and therefore has the same connotations as discussed previously. The flyer does, however, have a different photograph than the print advertisement. The photograph in Figure 4 shows a man and what appears to be a very young boy standing with their backs to the viewer. As with the previous example,

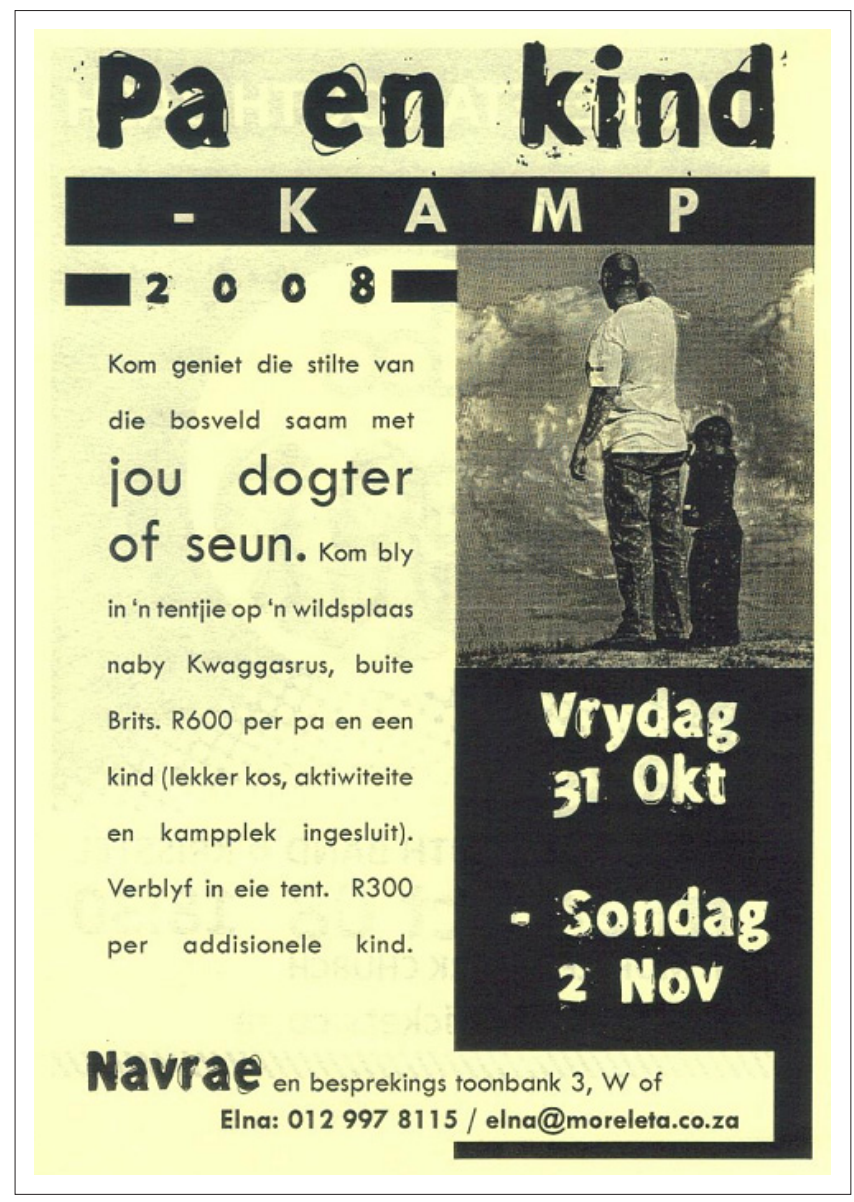

Used with permission by the Dutch Reformed Congregation Moreletapark.

FIGURE 4: Moreletapark 'Pa en kind-kamp' (Father and Child Camp) flyer.

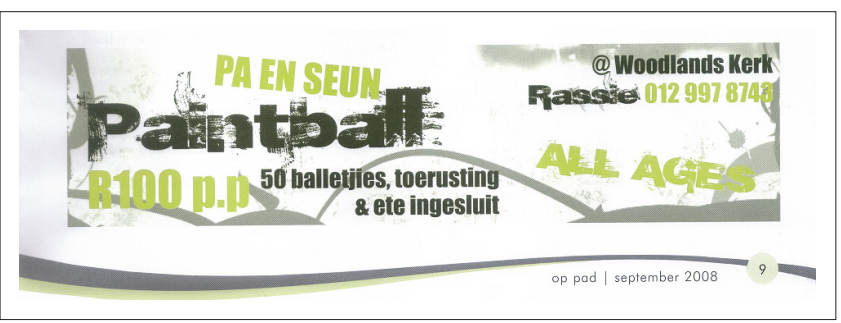

Source: Op pad, 2008a, September, p. 9

Used with permission by the Dutch Reformed Congregation Moreletapark.

FIGURE 5: Moreletapark 'Pa en Seun Paintball' (Father and Son Paintball) print advertisement in Op pad magazine, September 2008. we assume that they are father and son. We identify them both as male from their short haircuts, loose-fitting t-shirts and trousers. They appear to be standing on a hill top on the grass, thus outdoors, and the father is pointing at something in the distance in front of him with his right hand. When inspected closely, he also seems to be wearing sunglasses, connoting that he is outdoors in the sunlight, like the father in the print advertisement for this camp.

In terms of these two advertisements (Figures 3 and 4) for the Moreletapark Father and Child Camp, it is noteworthy that although the text takes pains to point out that fathers can bring their sons and/or daughters to the camp, the photographs used in the advertisements suggest something else. Not a single girl is depicted in either of these advertisements. Fathers appear to be camping with their sons, and not their 'children' - the inclusive term used in an attempt to be gender-neutral. The fact that camping fathers are only portrayed with their sons conveys the stereotypical idea that girls would prefer not to go camping, for this would mean getting dirty and giving up comforts. In this context, the text, which seems to be paying lip service to gender inclusivity, gives the idea that girls would be tolerated at the camp if they were to decide to go (which seems unlikely judging from the photographs used), or more importantly, if a father does not have a male child to bring along. One suspects that the attempt at gender-neutrality in these advertisements is not for the sake of daughters, but for the sake of son-less fathers, who would be excluded from the camping activity, were it called a father and son camp.

In both Figures 3 and 4 one sees fathers portrayed in a public (versus domestic) context of physical endurance and challenge, as described by Prinsloo (2006:134). Although fathers are very much present, involved and even nurturing, these images perpetuate myths of male physical prowess, male propensity towards outdoor activity and adventure as well as male conquest of nature. These myths are enforced in a parental context where bonding occurs between fathers and their sons. These myths of masculinity support the myth that the female is the weaker, less active and more domesticated sex, and are therefore part of the ideology of male physical dominance. It is also worth mentioning that in our larger study of gender representation in these churches, masculinity is most frequently portrayed in relation to physical activity and adventurism, and femininity is most frequently portrayed in terms of beauty, decoration and passivity, to which we return later.

Figure 6 is a file for materials used in Moreletapark's Baptism Course (Doopkursus). The bottom of the file is populated by various human figures. To the left there is an adult woman holding a baby. From the context of the file, we assume she is the newborn child's mother and she is wearing a wedding ring, rendering her a legitimately 'wed' mother in this conservative context. The woman's eyes are closed and she gently and lovingly embraces her precious new baby. She is dressed in white and the baby is wrapped in a white towel, which symbolises the purity and innocence of the newborn. 


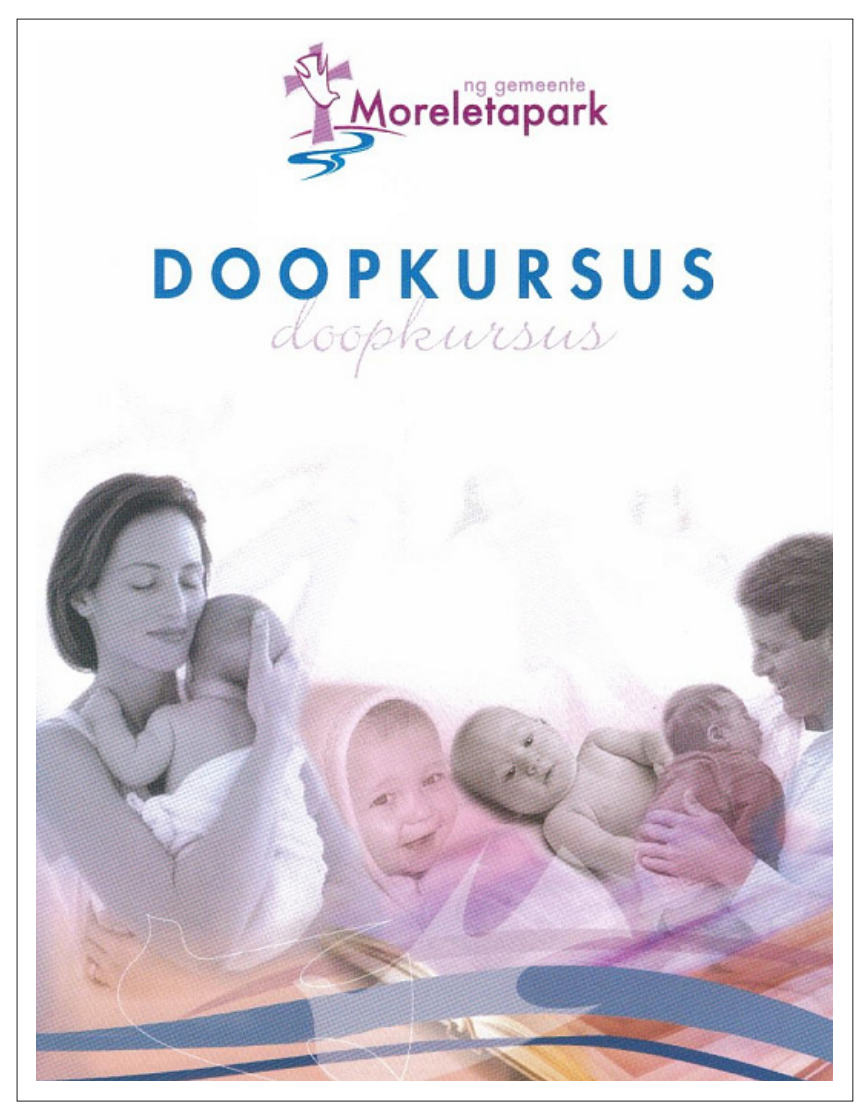

Used with permission by the Dutch Reformed Congregation Moreletapark.

FIGURE 6: Moreletapark 'Doopkursus' (Baptism Course) file.

To the right there is an adult male also holding a baby and one assumes that he is the father of the child. He is dressed in a buttoned-up shirt, which serves to signify his masculinity. The baby wears a sweater and appears to be asleep on the chest of the father who is looking down on the infant adoringly. Judging from the content of this file, children are believed to be precious gifts from God, an idea which is commonly promoted in Christianity based on Psalm 127:3.

A visual separation between mother and father is constructed on the file. In fact, one cannot even be sure that they are a couple. From left to right the photograph on the file represents its human figures in the following sequence: mother-baby-baby-baby-baby-father. The assumed parents appear to be literally connected through the children, and the babies far outnumber the parents in this figure. Unless meant to signify quadruplets, this over-abundance of babies on the Baptism Course material is rather peculiar given the fact that families in the Dutch Reformed Church seldom baptise more than one baby at a time, unless they are twins. This is because Dutch Reformed parents baptise their infants within the first couple of months after their birth. Siblings born apart are practically never baptised together, unless there are extraordinary circumstances involved. On the other hand, although perhaps not intended, the visual separation of the male and female figures on this file could hold subversive implications for traditional Christian configurations of the family as it might be seen to affirm the existence of single parent families.
The Baptism Course file presents the only unit of analysis in the data set of the entire study that depicts a man with a baby. In this light, the image should be lauded in the sense that it represents new possibilities for fathers and contributes to an expansion of the repertoire of roles represented for fathers. This single image does, however, stand in stark contrast to the multitude of images in the data set that show women with babies. (For the sake of brevity, we do not include and discuss these examples in this article.) Although portrayed with a baby, the father in this baptism file forms a rather small part of the composition. In literal terms, only about a quarter of his body is actually represented and he is much less prominent than the mother figure. This reinforces the stereotypical, patriarchal and essentialist idea that women are the primary caregivers to children, and indeed infants and fathers are not as important in this equation as mothers are. These views form the basis for essentialist beliefs on parenting, whereby women are relegated to the perpetual childcare roles.

The low visual prominence of the father in this file as well as the fact that there are no other representations of fathers with infants in the data set of the larger study, visually excludes fathers in the churches in this article from 'new fathering' practices where newborns are concerned. This negotiated visual construction of fatherhood is significant, as the literature suggests that 'new fathers' derive from the affluent middle-class. The church members of Moreletapark, kerksondermure and Doxa Deo are, almost without exception, fairly prosperous, middle-class, White Afrikaans-speakers from Pretoria East and Centurion suburbia. This poses the question as to why men are not represented as involved with infant childcare, as (1) men are represented as nurturing and involved fathers in the images discussed in this article and (2) given their demographic positioning, the men in these churches are quite likely, in theory, to engage in 'new fathering'. It would appear that the churches espouse, on a representational level at least, conservative values around traditional, essentialist parenting roles and patriarchal notions of the proper, nuclear family - especially where primary infant care is concerned.

The following section provides a further discussion of the findings regarding the representation of fatherhood in the visual culture of the three churches investigated. This section places these findings in the context of the larger study of which these images form part and problematises these findings in the context of the larger study.

\section{Discussion}

As in the mainstream media, the data from the three selected churches collected for the larger study show a representational preference for dominant masculinity. Dominant masculinity's pervasive power is enshrined by prolific media representation (Craig 1992; MacKinnon 2003), and this seems to be the case in the three churches as well. MacKinnon (2003:9) believes that hegemonic or dominant masculinity is embedded in representational practice in general. Posner (1995:22) further 
asserts that the West has enormous investment in the maintenance of mainstream masculinity, that is, White, heterosexual and dominant masculinity. In this regard, the churches in this study appear to participate in Western conceptions about dominant masculinity, as they uphold this brand of masculinity as an ideal to their audiences or congregations, by giving it representational priority and lending it legitimacy through signification. One might argue that the practical non-representation of nurturing fatherhood in relation to infant care in these churches results from this preference for dominant masculinity in representational practice. This also appears to be the case in the Art History canon, in which fathers are commonly portrayed in dominant and tough roles (cf. Duncan 1993:27-56), in opposition to nurturing motherhood roles, most frequently found in the Madonna-child configuration.

Furthermore, the visual material produced by the three churches investigated in the study on which this article is based accentuates men's public lives, especially in relation to their careers and individual pursuit of success; they are conceptualised as heroes, leaders, businessmen and breadwinners (Koenig-Visagie 2012a). As mentioned in the introduction, the representation of masculinity in this study was conceptualised according to three themes, namely professional occupation and leadership, physical activity and adventurism, and fatherhood. Although the study was conducted in a qualitative paradigm, it is noted that relatively few images of fatherhood were collected with the data, especially when compared to the number of images found related to the theme of physical activity and adventurism. This tendency of the churches in this study to represent men mainly in relation to physical activity and adventurism thus reinforces Prinsloo's (2006:134) view that there is a representational tendency in the media to locate fathers in settings of challenge and physical endurance.

A number of representational tendencies can, however, be identified from the manner in which fatherhood is represented by Moreletapark and kerksondermure. Depictions of the beloved patriarch are common in the churches (see, e.g. Figures 1 and 2). Fathers are portrayed as actively involved in the family unit and in parenting, and it could thus be said that certain progressive aspects of the 'new man' ethos manifest in the visual culture of Moreletapark and kerksondermure. The sensitive man and nurturing father are indeed prominent types found in constructions of the 'new man' (McKay, Mikosza \& Hutchins 2005:281). It is positive that in contrast to what Prinsloo (2006:132) highlights as the main problems with the representation of fathers in the South African mainstream media, two of the churches in this study do include fatherhood in their visual repertoire and also offer alternatives to violent macho roles so often offered to men, thereby expanding the visual scope for paternal roles.

Nonetheless, although fatherhood is depicted in this study's visual data, it is constructed distinctly from motherhood, as women are most likely to be shown in relation to babies and young infants whereas men are mostly associated with older children (Koenig-Visagie 2012a:202). This representational practice is problematic as it perpetuates the cultural myth of the female as primary caregiver who is concerned with the basic aspects of raising children (LaRossa 1995:451). The only emphasis regarding fathers' relationship with their children in our study is placed on the father-son relationship, which is portrayed in relation to male bonding and masculine sexual socialisation activities, such as camping and outdoor adventure, from which women are excluded. Viljoen (2011:324) maintains that in MaksiMan magazine, 'sport serves as an entry point into the difficult business of fatherhood.' This appears to be the case in Moreletapark and kerksondermure as well, as many of the images associated with fatherhood contain references to physical activity.

In her analysis Viljoen (2011:324) finds that emphasis is placed on fathers as financial providers for their families, and on their wives as primary caregivers. Prinsloo (2006) echoes this by stating that this:

hegemonic frame tends to constitute a 'good' father as the responsible breadwinner/provider and the protector ... In contrast, the 'good' mother is defined in her ability to care for and nurture her family and sustain intimate relationships with them. (p. 134)

This issue is particularly prominent in Doxa Deo's case, where it is found that although mothers are represented, fathers are presumably not physically, but at least visually absent from the church's visual culture. Masculinity in the data obtained from Doxa Deo is, rather, visually associated with corporate masculinity and physical activity.

We thus maintain that in the examples discussed, fatherhood is visually sidelined in terms of infant care. Scholars like Cohen (1990:172), point out that the feminisation of the family and of the home results in the undervaluation and marginalisation of fathers. Literature also indicates that fatherhood is sometimes sidelined because it is perceived to be close to femininity (Prinsloo 2006:143) and is accordingly rejected by mainstream dominant masculinity. It could be that infant care is visually excluded from portrayals of fatherhood in this study, as it is ideologically devalued as a 'feminised' practice.

Some scholars are concerned that the 'new man' phenomenon is but a construction of the media (see, e.g. McKay et al. 2005:281), with low correlation between the 'new man' as he is constructed in popular media narratives and tangible changes in real-life gender relations in the family. Perhaps this is due to the fact that dominant masculinity does not easily accept change (Whitehead 2002:154), as shown in our larger study through the manner in which male leadership is visually conceptualised in the three churches as spanning three spheres, namely the home, the church and the workplace (Koenig-Visagie 2012a:162, 206).

One could thus say that the presence of the new man or new father paradigm in the images discussed in this article represents both the negative and positive aspects of this paradigm. Fathers are represented as present, engaged and 
involved in the family, and for this positive representation of domestically engaged fatherhood these images deserve to receive some credit. The myth of the happy (nuclear) family is referred to and is not intended as a criticism, necessarily, but it has also been pointed out that in the context of these images, patriarchy and compulsory heterosexuality are upheld by this myth. Although fathers are shown in a family context and sometimes alone with their children, they are not portrayed as being involved in primary infant care, as opposed to various images of mothers found in the larger data set engaged in infant care and in taking care of others, such as the elderly or the needy. These representations share the problems described with the new man or new father paradigm in the first half of the article, in that they seem progressive as they show men as nurturing fathers and involved in the family unit, but because this nurturance is limited and excludes infant care, its progressive potential is diffused and appears merely symbolic, affording men more cultural capital with no actual power trade-off for women. The lack of this trade-off becomes even more evident when one considers the manner in which women and femininity are represented in the larger study: as passive and decorative, as a symbol for spirituality, as mothers and as taking care of others (cf. Koenig-Visagie 2012a). It is obvious that the presence of the new man or new father paradigm in the visual culture of these churches does not translate into a broadening of the scope of roles in which women are portrayed.

\section{Conclusion}

This article considered the representation (and nonrepresentation) of fatherhood in the visual culture of three Afrikaans churches, namely Moreletapark, kerksondermure and Doxa Deo. The images we discussed form part of visual data collected for a larger study, which investigates the representation of masculinity and gender in general. The images were analysed using a visual Barthean semiotic framework. The data in this study differs from that of studies conducted on the mainstream media in that fatherhood is represented more frequently (cf. Prinsloo 2006:132).

Although fathers are present in the data in this study, they are conspicuously absent from infant care, especially in comparison with how mothers are commonly represented in the study in relation to infant care. The preferred depiction of men as breadwinners and heads of households by the three selected Afrikaans churches maintains the 'masculine masquerade' (Brod 1995:13) of heroic masculinity predicated on activity, adventurism, success and careerism.

We have argued that although men are depicted as involved parents, there are certain limitations and exclusions to this involvement. Even though men are portrayed as domestically concerned and engaged parents, certain problematic elements of the new man paradigm are visible in the visual culture of these three churches, whereby patriarchy is upheld. Thus, whereas the mainstream media under- and misrepresents fatherhood, the church imagery discussed in this article does represent involved fatherhood, but in a restricted and patriarchally complicated way. If Christian visual texts provide some of the few depictions of fatherhood in the South African visual culture landscape, then perhaps less-conservative representations of fathers that are indeed involved in the full spectrum of child care practices are called for.

\section{Acknowledgements Competing interests}

The authors declare that they have no financial or personal relationship(s) that may have inappropriately influenced them in writing this article.

\section{Authors' contributions}

J.v.E. (University of Pretoria) was the supervisor of L.H.K.V.'s (University of South Africa) MA dissertation on which this article is based. The data collection and analyses were performed by L.H.K.V. and supervised by J.v.E. Both authors compiled the manuscript for this article.

\section{References}

Aronsohn, L. \& Lorre, C. (prods.), 2003-2012, Two and a half men, CBS Broadcasting Incorporated.

Barthes, R., [1957] 1972, Mythologies, transl. A. Lavers, Hill \& Wang, New York, NY. PMid:4573281

Brittan, A., 2001, 'Masculinities and masculinism', in S.M. Whitehead \& F.J. Barrett (eds.), The masculinities reader, pp. 51-55, Polity, Cambridge.

Brod, H., 1995, 'Masculinity as masquerade', in A. Perchuk \& H. Posner (eds.), The masculine masquerade: Masculinity and representation, pp. 13-19, The MIT Press, London \& Cambridge, MA.

Butler, J., 1990, Gender trouble: Feminism and the subversion of identity, Routledge, New York, NY.

Clare, A., 2000, On men: Masculinity in crisis, Chatto \& Windus, London.

Cohan, M. \& Hunter, B. (prods.), 1984-1992, Who's the boss?, America Broadcasting Company.

Cohen, D., 1990, Being a man, Routledge, London.

Craig, S. (ed.), 1992, Men, masculinity and the media: Research on men and masculinities, Sage, Newbury Park, CA.

Day, R.D. \& MacKey, W.C., 1986, 'The role of the American father: An examination of a media myth', Journal of Comparative Family Studies XVII(3), 371-388.

Duncan, C., 1993, The aesthetics of power: Essays in critical art history, Cambridge University Press, Cambridge.

Du Pisani, K., 2001, 'Puritanism transformed: Afrikaner masculinities in the apartheid and post-apartheid period', in R. Morrell (ed.), Changing men in Southern Africa, pp. 157-175, Natal University Press, Scottsville \& Zed, London \& New York, NY.

Faludi, S., 2000, Stiffed: The betrayal of modern man, Vintage, London.

Gordon, J. \& Speck, W. (dirs.), 2010, The switch, 20th Century Fox Studios.

Koenig-Visagie, L.H., 2012a, 'Significant Others: A visual analysis of the representation of gender in the Afrikaans corporate church', MA dissertation, Department of Visual Arts, University of Pretoria.

Koenig-Visagie, L.H., 2012b, 'The representation of gender in the Afrikaans corporate church: Fundamental difference', in J. Caartsens \& S. Viljoen (eds.), Sacred Selves: Essays on gender, religion and popular culture, pp. 159-186, Griffel, Cape Town.

ksm, 2008, Oktober (53), p. 1.

LaRossa, R., 1995, 'Fatherhood and social change', in M.S. Kimmel \& M.A. Messner (eds.), Men's lives, 3rd edn., pp. 448-460, Allyn \& Bacon, Boston.

MacKinnon, K., 2003, Representing men: Maleness and masculinity in the media, Arnold, London.

Marsiglio, W. \& Pleck, J.H., 2005, 'Fatherhood and masculinities', in M.S. Kimmel, L. Hearn \& R.W. Connell (eds.), Handbook of studies on men and masculinity, pp. 249-269, Sage, Thousand Oaks, CA. http://dx.doi.org/10.4135/9781452233833.n15

McKay, J., Mikosza, J. \& Hutchins, B., 2005, "'Gentlemen, the lunchbox has landed": Representations of masculinities and men's bodies in the popular media', in M.S. Kimmel, L. Hearn \& R.W. Connell (eds.), Handbook of studies on men and masculinity, pp. 270-288, Sage, Thousand Oaks, CA. http://dx.doi.org/10.4135/ 9781452233833.n16, PMid:16256211

Morgan, D.H.J., 2001, 'Family, gender and masculinities', in S.M. Whitehead \& F.J. Barrett (eds.), The masculinities reader, pp. 223-232, Polity, Cambridge.

Moreletapark Gemeente, Gesinsbediening, viewed 14 August 2008, from http://www. moreleta.org/NGGM/Users/PortalPageEdit.aspx?Cat=86\&SubCatID=81\&Menult em=Item_81 
Morrell, R., 2006, 'Fathers, fatherhood and masculinity in South Africa', in L. Richter \& R. Morrell (eds.), Baba: Men and fatherhood in South Africa, pp. 13-25. HSRC Press, Cape Town.

Op pad, 2008a, September, p. 9.

Op pad, 2008b, Oktober, p. 11.

Ortner, S.B., [1972] 1998, 'Is female to male as nature is to culture?', in L.J. Peach (ed.) Women in culture: A Women's Studies anthology, pp. 23-44, Blackwell, Malden, MA.

Posel, D. \& Devey, R., 2006, 'The demographics of fathers in South Africa: An analysis of survey data, 1993-2002', in L. Richter \& R. Morrell (eds.), Baba: Men and fatherhood in South Africa, pp. 38-52. HSRC Press, Cape Town.

Posner, H., 1995, 'The masculine masquerade: Masculinity represented in recent art', in A. Perchuk \& H. Posner (eds.), The masculine masquerade: Masculinity and representation, pp. 21-30, The MIT Press, London \& Cambridge, MA.

Prinsloo, J., 2006, 'Where have all the fathers gone? Media(ted) representations of fatherhood', in L. Richter \& R. Morrell (eds.), Baba: Men and fatherhood in South Africa, pp. 132-146, HSRC Press, Cape Town.

Richter, L. \& Morrell, R. (eds.), 2006, Baba: Men and fatherhood in South Africa, HSRC Press, Cape Town.
Silverstein, L.B., Auerbach, C.F., Grieco, L. \& Dunkel, F., 1999, 'Do Promise Keepers dream of feminist sheep?', Sex Roles 40(9/10), 665-688. http://dx.doi.org/10.1023/ A: 1018852500604

Springer, K.W., 2007, 'Breadwinner anxiety and husbands' health: How old ideas of masculinity can hurt', paper presented at the 102nd American Sociological Association Annual Meeting, Hilton New York \& Sheraton New York, New York City, 11-14 August.

Viljoen, S., 2008, 'New masculinities in a vernacular culture: A comparative analysis of two men's lifestyle magazines', PhD thesis, University of Cape Town, Cape Town.

Viljoen, S., 2009, 'From bedroom to boardroom: Corporate culture in two South African glossy men's magazines', in A.A. du Preez (ed.), Taking a hard look: Gender and visual culture, pp. 103-128, Cambridge Scholars, Newcastle upon Tyne.

Viljoen, S., 2011, “'Papa don't preach”: Fatherhood in a South African Christian men's magazine', Communicatio 37(2), 308-331. http://dx.doi.org/10.1080/02500167. 2011.576349

Weitz, C. \& Weitz, P., 2002, About a boy, film, Universal Pictures.

Whitehead, S.M., 2002, Men and masculinities: Key themes and new directions, Polity, Cambridge.

Whitehead, S.M. \& Barrett, F.J. (eds.), 2001, The Masculinities reader, Polity, Malden, MA 